\title{
A bioeconomic model for analysis of integrated weed management strategies for annual barnyardgrass (Echinochloa crus-galli complex) in Philippine rice farming systems
}

Jesusa C. Beltran ${ }^{*},{ }^{1,2}$, David J. Pannell ${ }^{1,3}$, Graeme J. Doole ${ }^{1,4}$, and Benedict White ${ }^{1}$

\begin{abstract}
This paper describes a dynamic simulation model that allows for comprehensive assessment of integrated weed management programmes for the control of annual barnyardgrass (Echinochloa crus-galli complex) in Philippine rice farming systems. The main outputs of the model include weed seed and plant densities and seasonal and annualised profit over the simulated planning horizon. Results broadly indicate that a mixture of chemical and non-chemical treatments provides good weed control in rice crops, and maximises long-term profit for systems where the main weed is annual barnyardgrass. However, the performance of this strategy is heavily influenced by crop establishment method and labour cost. At current labour cost and low weed density, the regular use of manual weeding is the most valuable primary form of weed control in rice farming systems, relative to herbicide application. Herbicide application becomes more profitable than manual weeding when labour costs increase or the population of barnyardgrass plants is not maintained at its optimal level. These results illustrate the value of the model for guiding the efficient control of annual barnyardgrass in rice crops in the Philippines.
\end{abstract}

Key words. Barnyardgrass; bioeconomic model; integrated weed management; rice farming.

\footnotetext{
* Corresponding author. jcbeltran20@yahoo.com

Published as: Beltran, J.C., Pannell, D.J., Doole, G.J. and White, B. (2012). A bioeconomic model for analysis of integrated weed management strategies for annual barnyardgrass (Echinochloa crus-galli complex) in Philippine rice farming systems, Agricultural Systems 112(1), 1-10.

${ }^{1}$ School of Agricultural and Resource Economics, Faculty of Natural and Agricultural Sciences, University of Western Australia, 35 Stirling Highway, Crawley, Western Australia 6009

${ }^{2}$ Philippine Rice Research Institute (PhilRice), Maligaya, Science City of Muñoz, Nueva Ecija, 3119, Philippines.

${ }^{3}$ Centre for Environmental Economics and Policy, School of Agricultural and Resource Economics, University of Western Australia, 35 Stirling Highway, Crawley, Western Australia 6009

${ }^{4}$ Department of Economics, Waikato University, Private Bag 3105, Hamilton, New Zealand.
} 


\section{Introduction}

The strong negative impacts that weeds can have on rice yields, and hence farm profits, create a demand for cost-effective weed management strategies. Worldwide losses in rice yields due to weeds have been estimated to be around 10 per cent of total production (Bastiaans and Kropff, 2003). Production losses due to weeds in rice crops are valued at around US\$30 billion annually, highlighting the strong economic incentives accruing to the employment of effective weed control.

Manual weeding has been commonly used in rice fields to minimise yield losses from weed competition. However, declining labour availability for agriculture, increasing labour costs related to reduced labour supply, and water scarcity have required rice producers to look for alternative weed-control treatments. Selective herbicides have been extensively used, given their ease of application, high efficacy, and low cost relative to alternative methods (Pingali et al., 1997). However, the use of herbicides has been accompanied globally by the potential build up of herbicide-resistant weeds, weed species population shifts, and concerns about environmental contamination and impacts on human health (Johnson and Mortimer, 2005).

Rice farmers throughout the Philippines have been encouraged by the Philippine Rice Research Institute (PhilRice) to use integrated weed management (IWM) strategies. This arises from dual objectives of maintaining yields and reducing unsustainable levels of herbicide application. IWM involves the use of a set of diverse weed control methods and may benefit the control of rice weeds by delaying the development of resistance and/or allowing the control of herbicide-resistant weeds. In most cases, economic considerations, particularly profit, are important to farmers in driving the adoption of agricultural innovations (Pannell et al., 2006). Nevertheless, the inherent complexity of identifying the relative benefits and costs of alternative IWM strategies makes it difficult to recognise the most profitable decisions (Doole and Pannell, 2008). Important drivers of this complexity are that the decision problem occurs over time and involves a high number of interrelated management strategies; the efficacy of these strategies is difficult to identify, especially when techniques are applied together; weed management and economic performance are interrelated; and understanding of the process of resistance development is complex and still evolving (Pannell, 2002). An additional difficulty in rice farming systems arises from the strong morphological resemblance of rice crops and annual weeds complicates weed control.

Bioeconomic models are an effective way to identify the relative profitability of alterative IWM strategies, despite this inherent complexity (Pannell et al., 2004; Doole and Weetman, 2009). Such models have been used previously to guide weed management on rice farms, such as RiceWeed (VanDevender et al., 1994). However, there is an apparent lack of a detailed model to inform IWM decisions both in rice farming systems, including in the Philippines. The objectives of this paper are to describe a weed control model constructed for a major weed of rice crops, to present its key assumptions, and to illustrate its use in the analysis of weed control problems. The model is constructed for annual barnyardgrass (Echinochloa crus-galli complex) on irrigated rice farms in the Philippines. Barnyardgrass is one of the most serious weeds of rice crops in this nation (De Dios et al., 2005). Incidence of butachlor+propanil-tolerant annual barnyardgrass has been reported in some important rice- 
growing areas of the Philippines (Juliano et al., 2010). Moreover, a focus on the control of this weed is of broad value since it affects rice yields in most rice-producing nations (Tran, 1997).

The paper is structured as follows. Section 2 includes an overview of the weed control model. The results of the analysis for standard model outputs are presented and discussed in Section 3, while those for the impacts of labour cost are presented and discussed in Section 4. Section 5 concludes the analysis.

\section{Model description}

\subsection{Overview}

Resistance and Integrated Management in the Philippines (RIMPhil) is a bioeconomic model developed to analyse the implications of IWM programmes for rice farming in the Philippines. It allows the evaluation of IWM strategies under a variety of circumstances, including diverse planting techniques and threats of herbicide resistance. The structure of the RIMPhil model is loosely based on that of the Resistance and Integrated Management (RIM) model, which was developed in Western Australia to guide the management of annual ryegrass (Pannell et al., 2004) and wild radish weeds (Monjardino et al., 2003). The model is implemented in Microsoft Excel ${ }^{\circledR}$ using formulae and Visual Basic macros.

RIMPhil is a dynamic simulation model that evaluates a range of potential weed management scenarios once they are entered manually by a user. The use of simulation generally allows the representation of greater complexity than can be attained in an optimisation framework. Optimisation techniques have been applied to identify near-optimal solutions in simulation models with a similar structure (e.g. Doole and Pannell, 2008). However, the number of possible treatment combinations in RIMPhil is so large that such search methods proved to be ineffective in the identification of optimal solutions. Thus, the best feasible strategies are determined for different situations through the simulation of alternative combinations of weed management treatments using informed trial and error, subject to a pre-determined sequence of planting methods. Concurrently, the user can view their predicted effects on the annual barnyardgrass population, grain yield, and profit over 5, 10, 15, and 20-year periods.

The user of RIMPhil can choose either transplanted or direct wet-seeded rice as a planting technique. Transplanting involves replanting rice seedlings grown in nurseries to puddled soil, while direct-seeding consists of sowing the pre-germinated and ungerminated seeds on a wet or dry puddled soil, respectively. Planting methods can be selected in the wet or dry cropping seasons defined in each year and impact weed population dynamics and economic outcomes. More profit is usually earned when the direct-seeding method is used because the high cost of labour required for transplanting is not incurred. However, weeds are a greater problem in direct-seeded rice, as crop and weeds germinate together and flooding for weed control is not possible.

The model user defines the maximum number of applications of each group of herbicides that can be used prior to the onset of herbicide resistance (Pannell et al., 2004). This is important given that herbicide resistance has 
recently been observed in barnyardgrass populations in the Philippines (e.g. Juliano et al., 2010). A wide selection of non-herbicide weed control options is included in the model, which permit the user to identify profitable substitutes as herbicide efficacy is lost.

The RIMPhil model incorporates around 300 parameters. These are defined for a typical lowland irrigated rice farm, but can be adjusted by the user. The model could readily be adapted to similar rice production systems in other countries. Standard data and information used in the model are collected from many different sources. These include research reports, scientist opinion, farmer opinion, and peer-reviewed literature (Section 2.7). A copy of the model and detailed information regarding the sources and magnitude of all parameters can be obtained from the primary author on request.

\subsection{Weed biology and ecology}

The genus Echinochloa is composed of about 50 species (Michael, 1983). Among the members of its genus, the most broad-based and economically important are the taxa of the Echinochloa crus-galli complex, which is widely known as barnyardgrass (Barrett and Wilson, 1981). Barnyardgrass is a competitive weed of rice crops given its rapid development to reproductive maturity, high phenotypic plasticity, abundant production of small seeds that are easily dispersed, germination flexibility, strong competitive ability, and substantial herbicide resistance (Moody, 1994). Moreover, it is indistinguishable from rice crops in its early vegetative phase, has an annual life cycle, and can germinate through an entire cropping season (Holm et al., 1977).

Barnyardgrass has a very high level of seed germination because spikelets are easily dispersed (Yabuno, 1983). In general, seeds of barnyardgrass have a relatively short dormancy of only a few months (Holm et al., 1977) and their soil persistence and viability are also short and limited (Valverde et al., 2000). However, broad variation is observed on farms given heterogeneity in temperature, light intensity and quality, nutrition, and seed depth (Egley, 1995). The majority of barnyardgrass seeds present in the soil germinate near the start of rice growth (between 2-3 weeks after planting or seeding) and only a few seeds germinate at the later life stage of the crop (De Datta and Baltazar, 1996). For example, Yabuno (1983) reported an average germination rate of 81 to 99 per cent within two weeks after flowering of the barnyardgrass plant. This highlights the capacity of barnyardgrass to compete with rice crops immediately, particularly so with direct-seeding.

Barnyardgrass also has a staggered germination that is initiated during the fallow period and before land is prepared for the subsequent cropping season. Expert opinion was used to generate suitable patterns of germination in the model and this was validated against what limited relevant trial data was available. In the model, a large cohort of approximately 30 per cent of the original seed bank is assumed to germinate during the fallow period. This is followed by a smaller cohort of about 2 per cent after cultivating the rice field. The largest cohort of around 51 per cent is assumed to germinate within two weeks (1-15 days) after transplanting (DAT) in transplanted crops or after sowing (DAS) in direct-seeded crops. A cohort of approximately 7 per cent is assumed to germinate between 16-30 DAT, followed by another smaller cohort of about 1 per cent between 3145 DAT. Before harvesting the crop, an additional 1 per cent of seeds are assumed to germinate. 
Barnyardgrass is a prolific seed producer, with seed production from a single plant ranging from 2,000 (Holm et al., 1977) to almost 5,000 seeds (Janiya and Johnson, 2008) in Philippine rice farming systems. Thus, barnyardgrass plants can yield as much as 48,000 seeds $\mathrm{m}^{-2}$ in a weedy rice crop (Holm et al., 1977).

\subsection{Major assumptions in the RIMPhil model}

The primary assumptions underlying the RIMPhil model are:

1. The model is deterministic and does not represent annual variations in weather, yield, prices, costs, and herbicide performance.

2. Potential weed-free yield varies between the wet and dry cropping seasons, with higher grain yield attainable during the dry cropping season.

3. It is assumed that the rice seed used is a modern inbred variety, requiring a period to maturity of 120 days.

4. Seeds are classified as poor or high quality seeds. Poor quality seeds (the default) are cheaper, but also attain lower yields and have greater weed contamination.

5. The assumed default tillage system is reduced tillage. This involves an initial cultivation around 7 to 10 DAT or DAS (Moody, 1990). Use of non-selective herbicide or full cultivation increase effective weed control, but are more expensive.

6. Weeds other than annual barnyardgrass do not impact crop yield.

7. Combined effects of different weed controls are multiplicative, rather than additive, as control treatments occur at different times (Pannell et al., 2004).

8. Default initial weed seed density is 200 seeds $\mathrm{m}^{-2}$.

9. Weeds that emerge early in the cropping season and survive grow larger and produce more seeds than later-emerging seedlings (Maun and Barrett, 1986).

10. Weeds that emerge and survive in direct-seeded rice are more competitive than in transplanted crops (De Datta and Baltazar, 1996).

11. There are five choices of seeding rates included in the model: 50 (default), 100, 150, 200, and $300 \mathrm{~kg}$ $\mathrm{ha}^{-1}$.

\subsection{Biology}

Weed population dynamics are defined through:

$$
W=S_{V} \times G_{I} \times\left(1-D_{F}\right) \times\left(1-D_{N}\right) \times\left(1-D_{H}\right),
$$

where $W$ represents the weed plant density that survives to maturity (plants $\mathrm{m}^{-2}$ ), $S_{V}$ is the number of viable weed seeds present at the start of the cropping season (seeds $\mathrm{m}^{-2}$ ), $G_{I}$ is the proportion of initial weed seed pool that germinates, $D_{F}$ is the proportion of germinated weed seeds that die naturally during the growing season, 
$D_{N}$ is the proportion of germinated seeds that are killed by non-chemical weed controls, and $D_{H}$ is the proportion of germinated seeds that are killed by herbicide application. Seeds from external sources are ignored given that the number of seeds from these sources is very low, relative to those produced by weeds in rice crops (Buhler et al., 1997).

Barnyardgrass population dynamics are defined across seven periods within each cropping season: (1) just before land preparation, (2) time for land preparation, (3) 15 DAT/DAS, (4) 30 DAT/DAS, (5) 45 DAT/DAS, (6) just before harvest, and (7) after harvest. This allows more accurate description of the evolution of the weed species across time.

The barnyardgrass plant density (plants $\mathrm{m}^{-2}$ ) for each period is calculated using:

$W_{C}=W_{P} \times\left(1-D_{N}\right) \times\left(1-D_{L}\right)+S_{P} \times G_{C} \times\left(1-D_{R}\right)$,

where $W_{C}$ refers to the number of germinated barnyardgrass plants alive (plants $\mathrm{m}^{-2}$ ) in the current period, $W_{P}$ is the number of barnyardgrass (plants $\mathrm{m}^{-2}$ ) surviving from early weed control treatments, $D_{N}$ is the proportion of barnyardgrass that die from non-chemical treatments, $D_{L}$ is the proportion of the barnyardgrass population that dies due to post-emergence herbicide treatments, $S_{P}$ refers to the number of barnyardgrass seeds that remained viable in the soil from the previous period, $G_{C}$ is the proportion of viable seeds that germinate, and $D_{R}$ is the proportion of germinated barnyardgrass seeds that die from the use of pre-emergence herbicides.

The actual number of barnyardgrass seeds produced (seeds $\mathrm{m}^{-2}$ ) during the cropping season $\left(S_{T}\right)$ is calculated using:

$S_{T}=S_{W P} \times W_{W S}$,

where $S_{W P}$ refers to the seeds produced per weed plant during the cropping season (see Eq. 4) and $W_{W S}$ is the number of weed setting seeds.

The impacts of a rice crop's competitive ability on the number of seeds produced (seeds $\mathrm{m}^{-2}$ ) per barnyardgrass plant $\left(S_{W P}\right)$ is captured in the equation:

$S_{W P}=S_{M S} \times\left(\frac{1}{a+W_{H B}+\left(b \times D_{D C}\right)}\right) \times \frac{W_{H B}}{W_{W S}} \times\left(1-D_{E}\right)$, 
where $S_{M S}$ represents maximum barnyardgrass seed production (seeds $\mathrm{m}^{-2}$ season ${ }^{-1}$ ), $a$ signifies the barnyardgrass background competition factor $(\mathrm{BBCF})$ that is used to calculate the base level of intraspecies competition affecting weed seed production, $W_{H B}$ refers to the healthy equivalent barnyardgrass population density (plants $\mathrm{m}^{-2}$ ) before harvest, $b$ is the rice crop competition factor on barnyardgrass (RCFB), $D_{D C}$ refers to the rice crop density depending on the seeding rate selected in the model, $W_{W S}$ is the number of barnyardgrass (plants $\mathrm{m}^{-2}$ ) surviving all of the treatments that occur before harvest, and $D_{E}$ represents the sublethal effect of selective herbicides that leads to lower seed production by weeds.

Rice yield depends on crop density and the competitive abilities of rice, relative to barnyardgrass, across planting techniques (Kropff and Lotz, 1993). The proportion of weed-free yield that exists after accounting for weed competition $\left(Y_{P R}\right)$ is calculated using:

$Y_{P R}=\frac{1+c}{D_{S R}} \times\left(\frac{D_{D C}}{c+D_{D C}+\left(d \times\left(W_{W S}+W_{W A}\right)\right)}\right) \times M_{Y L}+\left(1-M_{Y L}\right)$,

where $c$ refers to the rice crop background competition factor (RBCF), $D_{S R}$ represents the standard rice crop density (plants $\mathrm{m}^{-2}$ ) for each planting method (this is not the actual density, but a standard level for comparison), $D_{D C}$ refers to the actual rice crop density (plants $\mathrm{m}^{-2}$ ) depending on the seeding rate used, $d$ signifies the barnyardgrass competition factor in the rice crop (BCFR), $W_{W S}$ is the number of barnyardgrass plants (plants $\mathrm{m}^{-2}$ ) just before harvest, $W_{W A}$ refers to the number of barnyardgrass plants (plants $\mathrm{m}^{-2}$ ) that must be added to $W_{W S}$ to account for the yield loss that will be incurred with the late removal of weeds, and $M_{Y L}$ represents the maximum proportion of grain yield loss at high weed densities. The strong relationship between crop yield and weed density is shown in Figure 1. It is apparent how a high seeding rate can reduce yield losses through increasing competition with weeds in early growth stages.

[Insert Figure 1 near here]

\subsection{Treatment options}

There are a total of 49 weed-control treatments included in the RIMPhil model (Table 1). These treatments can be classified as herbicide and non-herbicide weed controls. There are 29 herbicide options and these are sorted into three separate groups: selective herbicides (24), non-selective herbicides with cultural methods (2), and user-defined selective herbicides (3). Selective and user-defined selective herbicide treatments in the model are grouped according to their time of application, these being: (1) pre-emergence herbicides with application time from 0-6 DAT/DAS, (2) early post-emergence herbicides with application times from 7-15 DAT/DAS, and (3) late post-emergence herbicides with application time from 16-30 DAT/DAS (De Datta and Baltazar, 1996). On 
the other hand, non-herbicide treatments included in the model are either cultural or manual methods. PhilRice (2001) provide detailed descriptions of these options.

[Insert Table 1 near here]

\subsection{Economics}

The model includes a wide range of relevant economic variables. Discounting is used to compare costs and benefits that occur at different times (Pannell, 2006). Discounted costs and benefits are summed to calculate the net present value (NPV), and the preferred strategy is that with the highest NPV.

Table 1 shows the calculated cost for each weed control method. The variable costs included in the model are the non-weed control costs (inputs and other production costs) and weed control costs (chemical and nonchemical weed control costs). For manual weeding, the costs associated are calculated by multiplying the total number of days required for weeding (man-days $\mathrm{ha}^{-1}$ ) by the prevailing wage rate. The total number of days required for manual weeding is calculated as the time required to remove each weed, multiplied by the number of weeds. The relationship between the time required per weed and weed density is negative and nonlinear. This means that as weed density increases, the average time required to remove a weed decreases, but at a decreasing rate. This nonlinear relationship is described through:

$T_{M W}=\alpha \times\left(E X P\left(-\omega W_{D}\right)\right)+\kappa$,

where $T_{M W}$ represents the time required to remove a weed per second (weed $\sec ^{-1}$ ), $W_{D}$ refers to the weed density (plants $\mathrm{m}^{-2}$ ), $\alpha$ and $\kappa$ represent constant parameters, and $\omega$ controls the change in the time required per weed given a unit change in weed density. The time required for manual weeding increases with directseeding because it is more difficult to distinguish weeds from rice plants with this crop-establishment method (Naylor, 1996).

Total grain gross receipts (PHP ha ${ }^{-1}$ ) are the returns received before the total grain production costs have been deducted. These values are estimated by multiplying the rice crop yield after weeds $\left(\mathrm{t} \mathrm{ha}^{-1}\right)$ by the net price of rice, with a default value of PHP12,500 $\mathrm{t}^{-1}$ (BAS, 2011). Net returns are estimated by subtracting total variable costs from total gross receipts. To calculate the annual gross margins, the net returns for both cropping seasons are added together.

Equivalent annual profit (EAP) is the level of constant annual profit that would provide the same NPV as the observed sequence of benefits and costs (Pannell, 2006). The calculation of EAP in RIMPhil takes account of the inflation rate on input costs and crop product prices. The assumed real discount rate used is 6 per cent (NEDA, 2010). Taxes paid on interest or income earned can be defined in RIMPhil. However, no taxes are represented in the general 
model since most farmers do not reach the income threshold required for taxation. An exogenous annual rate of yield increase of 2 per cent is also incorporated (PhilRice, 2007), reflecting the aggregated impact of research, development, and extension on crop production.

\subsection{Model validation}

Appropriate verification of a model involves reflection on the suitability of model structure, inputs, and outputs and whether it is adequate to fulfil its purpose (McCarl and Apland, 1986). The structure of the model and the parameters within RIMPhil are based on the best information available pertaining to rice farms in the Philippines. Weed population dynamics and control efficacy parameters have been drawn from extensive literature review and discussion with experienced weed scientists. The use of expert opinion to elicit appropriate functional form relationships and parameter values is a critical aspect of developing many such bioeconomic models, as it rare for appropriate validation data to be available given the large amount of information that comprehensive system models require and the limited scope of most experimental studies.

The biological output of the Western Australian version of RIM (Pannell et al., 2004) has been validated against field data (see Draper and Roy, 2002). The output of RIMPhil has not been validated in a similar way given the absence of equivalent information for the farming system described, particularly over a series of years. Such data limitations are indeed typical of most bioeconomic models (McCarl and Apland, 1986). However, after extensive review, RIMPhil has been assessed by weed scientists, especially those at PhilRice (Martin and Juliano pers. comm., 2010) to provide a meaningful and sensible description of annual barnyardgrass dynamics in this farming environment.

\subsection{Model runs}

Section 3 presents and discusses the analysis of the profitability of different weed management strategies, ranging from the most simple to the most profitable strategy (i.e. model standard results). The profitability of each strategy is measured based on the EAP ha ${ }^{-1}$ over a 20-year planning horizon, and all monetary values are presented in US dollars (US\$). For the purpose of this study, the exchange rate used for converting PHP into US dollars is US $\$ 1=\mathrm{PHP} 45$. All weed-control scenarios in these base-case results include a sequence of directseeding (wet season)-direct-seeding (dry season) (DD) methods of rice crop establishment in each year over a 20 -year horizon. The reason for focusing on direct-seeding is that it typically results in a higher weed density than in transplanted crops, so weed-control is a more pertinent issue.

Two farming systems are used in Section 3 to evaluate the performance of different combination of weedcontrol treatments: conventional (CFS) and innovative (IFS) farming systems. The CFS includes the traditional rice production practices of Filipino rice farmers; this involves reduced tillage, poor quality seeds, and use of a high seeding rate $\left(150 \mathrm{~kg} \mathrm{ha}^{-1}\right)$. On the other hand, IFS includes technologies currently recommended as best management practices, such as full or thorough land preparation, certified or high quality seeds, and use of a low seeding rate $\left(50 \mathrm{~kg} \mathrm{ha}^{-1}\right)$. Both farming systems employ manual broadcasting for the sowing of seed. 
The impacts of increasing labour cost on the most-profitable weed control strategy is evaluated in Section 4 for scenarios with differing levels of weed density levels. Three labour prices are used in the analysis, these being: (1) current labour cost (base-case), (2) higher labour cost (100 per cent increase in the current price), and (3) very high labour cost (200 per cent increase in the current price). Scenarios 2 and 3 are realistic based on the increasing trend observed in the nominal wage rate in the Philippines. It is expected that they could be observed within 5 to 10 years. All weed-control scenarios are based on the DD scenario listed above, as direct-seeding reduces labour demand.

To improve understanding of how these model outputs change with perturbations to key parameters, a sensitivity analysis is performed using a process recommended by Pannell (1997). This procedure involves the definition of different potential levels of input coefficients, use of sensitivity indices to highlight which parameters have the greatest impact on model output, and performing a full factorial experiment to highlight the impact of the most responsive parameters on model output. The most important uncertain model parameters identified in the sensitivity analysis have an absolute sensitivity index value equal to or greater than 0.2. This indicates that each perturbation incurs at least a US $\$ 20 \mathrm{ha}^{-1}$ change in EAP per cropping season, or about US\$40 $\mathrm{ha}^{-1}$ annually over 20 years. The parameters that equal or exceed this threshold (and so used in the full factorial experiment) are: (a) base weed-free yield, (b) net sale price of rice crop, (c) barnyardgrass seed production, (d) maximum barnyardgrass seed production, (e) rice crop competition factor on barnyardgrass, and (f) discount rate.

\subsection{Limitations}

A number of the assumptions listed in section 2.3 impose limitations of various kinds on the model. They are made, variously, for reasons of tractability, ease of use or lack of better information. In addition, the follow points outline further limitations to the scope of the model.

RIMPhil represents the level of herbicide resistance through defining the number of applications within each herbicide mode of action available before resistance develops. The model could potentially be extended to include the genetics of resistance to represent resistance development in more detail.

RIMPhil represents only a single field. Some weed management strategies may involve changes in crop management that have whole-farm implications. However, the small size of most rice farms reinforces the suitability of the single field approach, and this method also promotes tractability.

RIMPhil focuses on a single crop and a single weed species. In reality, there are other crops that can be used instead of rice (e.g. corn (Zea mays)) and weed species other than barnyardgrass (e.g. weedy rice (Oryza spp.)). The model could be extended to include a selection of profitable crop rotations and the management of multiple weed species.

RIMPhil model is representative of a typical irrigated field in the Philippines. Of course, there is substantial diversity in important biological and economic relationships between rice farming systems. However, the model 
is designed to overcome this limitation by allowing the user to specify the parameter values that best describe their particular farm situation.

Despite substantial efforts spent on data collection, there is still uncertainty about some of the parameters and relationships represented in RIMPhil. Although a comprehensive sensitivity analysis is conducted, additional field experiments addressing key knowledge gaps could help improve precision.

\section{Standard model results}

In the first two rows of Table 2, economic and weed density results are shown for scenarios where no specific weed-control treatments are used. In these scenarios, the estimated EAPs are -US\$293 ha-1 and -US\$210 ha-1 for CFS and IFS, respectively. The reason for these negative profits is the high weed densities in the absence of weed control: around 21,000 plants $\mathrm{m}^{-2}$ for CFS and 16,000 plants $\mathrm{m}^{-2}$ for IFS. The results highlight the competitiveness of barnyardgrass relative to rice, and therefore emphasise the importance of effective weed management.

[Insert Table 2 near here]

The weed management strategies presented in Table 2 are classified into three major groups: (1) chemical control, (2) non-chemical control, and (3) combination of chemical and non-chemical controls. The profitability and terminal weed density experienced under a range of different weed-control scenarios in these categories are provided in Table 2 and are further elaborated in the following subsections.

\subsection{Chemical control}

The profitability of relying solely on chemicals to manage weeds in rice production is examined here. In these scenarios, it is assumed that the continuous use of the same group of herbicides over 20 years will not develop herbicide resistance. The chemical control strategies presented here vary in terms of timing of application and frequency of use.

Application of pre-emergence herbicides (PEH). In scenario $1 \mathrm{a}$ and $1 \mathrm{~b}$, pre-emergence herbicide (i.e. butachlor+safener) is applied in each cropping season to manage the weed problems in both farming systems. With these methods, the EAPs are slightly improved to $-\mathrm{US} \$ 247 \mathrm{ha}^{-1}$ for scenario 1a and -US\$184 ha ${ }^{-1}$ for scenario $1 \mathrm{~b}$. The profits are still negative because of the large number of barnyardgrass plants that still infest the rice crops (Table 2).

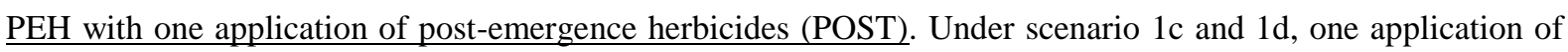
POST per cropping season, as the primary means of weed control, is included in the previous scenarios (1a and 1b). Using these methods, the EAPs are significantly increased to US $\$ 1,043 \mathrm{ha}^{-1}$ and US $\$ 402 \mathrm{ha}^{-1}$ for scenario 1c and 1d, respectively. The final weed densities in these scenarios are also substantially reduced, indicating the efficacy of these chemicals. On the other hand, the calculated profit in scenario $1 \mathrm{c}$ is higher than in scenario 1d, largely because of the use of a high seeding rate in the former setting, which enhances the competitiveness of 
rice, relative to barnyardgrass. Thus, the low seeding rate that is currently recommended by PhilRice is not necessarily the most beneficial strategy.

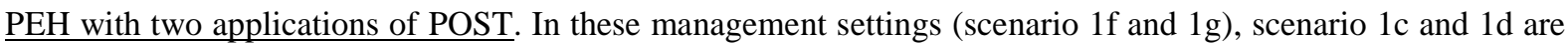
expanded by the inclusion of another POST application per season. This approach led to a considerable increase in the EAPs over 20 years in scenario $1 \mathrm{f}$ and scenario $1 \mathrm{~g}$. Similarly, these methods achieved the highest rate of barnyardgrass mortality, indicating their dual benefits and reinforcing that a key impact of weed management on farm profits is through yield loss.

\subsection{Non-chemical control}

The following scenarios are used to investigate the profitability of using non-chemical control measures. It is assumed that the weed-control methods selected for each scenario are the same in every year over 20 years.

Use of water management. In scenario $2 \mathrm{a}$ and $2 \mathrm{~d}$, irrigating the rice field during 7-10 DAS at 2-3 $\mathrm{cm}$ water depth and raising this water level as the crop develops is the only method used in managing weeds per cropping season in both farming systems. EAP does not improve and remain negative for both scenario $2 \mathrm{a}$ and $2 \mathrm{~b}$ (Table 2). The estimated values of EAP become even more negative when water management is replaced by the use of the mechanical stale-seedbed method in CFS (scenario 2c) and IFS (scenario 2d) because the latter approach is more costly, and also less effective at reducing weed populations.

Use of water management with two applications of manual weeding. Manual weeding is used as the primary means of weed control for every cropping season in scenario $2 \mathrm{~g}$ and $2 \mathrm{~h}$. In this model, the estimated cost of manual weeding excluded the costs associated with labour used for search and monitoring. The use of a mechanical seeder (i.e. drumseeder) for sowing the rice seeds is necessary to facilitate the use of manual weeding. Therefore, manual broadcasting is replaced by the use of drumseeder in these scenarios. These strategies have very low weed densities and relatively high profitability: US\$1,245 $\mathrm{ha}^{-1}$ for scenario $2 \mathrm{~g}$ and US\$1,518 $\mathrm{ha}^{-1}$ for scenario $2 \mathrm{~h}$. These results highlighted the importance of the drumseeder for enhancing the effectiveness of manual weeding in direct-seeded rice. However, the adoption of drumseeders in the country is still low. This is primarily because a drumseeder is more capital intensive and technical to use, relative to manual broadcasting.

The use of a single manual weeding per season in both farming systems (i.e. scenario $2 \mathrm{e}$ for CFS and scenario $2 \mathrm{f}$ for IFS) is also examined. Results show very high decreases in profits because there are so many weeds in the field (compared to $2 \mathrm{~g}$ and $2 \mathrm{~h}$ ), making manual weeding very expensive - the labour requirement of manual weeding is highly dependent on weed density. On the other hand, if two weedings per season are used (strategies $2 \mathrm{~g}$ and $2 \mathrm{~h}$ ), weed density is maintained at a low enough level for hand weeding to be profitable. EAP values, however, will drop to some extent if a mechanical weeder (i.e. rotary weeder) replaces manual weeding as the direct means of weed control (scenario $2 \mathrm{i}$ and $2 \mathrm{j}$ ).

3.3 Non-chemical and chemical control 
As emphasised in many studies, relying on one method of control may be less effective than a combination of methods. For example, a high dependence on chemicals alone will lead to a build up of resistance, whereas dependence solely on non-chemical options may be very costly as these are labour intensive. Therefore, results are presented for a mixture of chemical and non-chemical weed control methods. Note that the main difference between the profitable integrated weed control strategies presented here is the choice of the primary means of weed-control from the three direct methods: manual weeding, post-emergence herbicides (POST) application, and mechanical weeding.

Use of water management with PEH application. The applications of both water management and PEH as weed control strategies per season in both farming systems have produced higher EAP values (-US\$191 ha- ${ }^{-1}$ for scenario $3 \mathrm{a}$ and -US $\$ 154 \mathrm{ha}^{-1}$ for scenario $3 \mathrm{~b}$ ), relative to their separate individual applications: scenarios 1a and $1 \mathrm{~b}$ for PEH application and scenarios $2 \mathrm{a}$ and $2 \mathrm{~b}$ for use of water management. The profits are still negative because unaccompanied water management and $\mathrm{PEH}$ applications are not enough to control the large number of barnyardgrass plants in the field.

Use of water management with PEH and one manual weeding applications. Scenario $3 \mathrm{a}$ and $3 \mathrm{~b}$ are extended by the incorporation of one manual weeding in both CFS (scenario 3c) and IFS (scenario 3d). When one manual weeding per season is integrated with PEH application, this method is both effective and increases profit significantly. The profitability of a single manual weeding per season contrasts with the earlier result when manual weeding was not combined with chemical control (see scenarios $2 \mathrm{e}$ and $2 \mathrm{f}$ ). Inclusion of another application of manual weeding (i.e. a total of two hand weedings per season) into scenarios $3 \mathrm{c}$ and $3 \mathrm{~d}$ increased the EAPs to more than US\$1,500 $\mathrm{ha}^{-1}$ for both scenario 3e and 3f. Improvement in profit is due to reductions in labour cost, as the labour requirement is less when weed density is minimal.

Use of water management with PEH and one mechanical weeding applications. In these scenarios, manual weeding is replaced by the use of mechanical weeding in both the CFS (scenario $3 \mathrm{~g}$ ) and IFS (scenario $3 \mathrm{~h}$ ). Implementing these strategies would significantly reduce long-term profits, relative to strategies in scenario $3 \mathrm{c}$ and $3 \mathrm{~d}$ that utilise manual weeding. Nevertheless, if an additional use of mechanical weeding per season is included in both scenario $3 \mathrm{~g}$ and $3 \mathrm{~h}$, the calculated EAP would increase from US\$413 ha-1 (scenario $3 \mathrm{~g}$ ) to US\$1,462 $\mathrm{ha}^{-1}$ (scenario 3i). Similar results are observed for IFS if two applications of mechanical weeding are used per season (scenario $3 \mathrm{j}$ ) instead of one (scenario $3 \mathrm{~h}$ ).

Use of water management with PEH and one POST applications. Instead of manual and mechanical weeding, POST application is used as a direct weed control measure in both CFS (scenario 3k) and IFS (scenario 31) in these simulations. The use of PEH with water management plus one POST application maximises the EAP in both scenarios (Table 2). On the other hand, increasing the frequency of POST application to two applications (scenario $3 \mathrm{~m}$ and $3 \mathrm{n}$ ) would reduce profit because good barnyardgrass control is already achieved with a single POST application. This result highlights the diminishing or negative marginal profit associated with implementing additional control strategies once the number of weeds is at a very low level. 
Overall, the best strategy of those discussed so far is $3 \mathrm{e}$, consisting of the use of a water management, a drumseeder, two manual weedings per season, and an application of a pre-emergence herbicide. This strategy produces the highest value (US\$1,529 ha-1) of EAP (Table 2).

\section{Impacts of high labour cost and high weed density}

This section reports and discusses the implications of model results concerning the impacts of increasing labour cost for the management decisions of rice farmers in the Philippines, particularly those concerning the trade-off between the use of manual weeding and post-emergence herbicides to control weeds.

Table 3 shows the economic implications of timely manual weeding and use of post-emergence selective herbicides in one cropping period under different weed densities across different labour costs. Under current labour costs (base-case), with low weed density, the treatment costs for manual weeding (US\$34 ha-1) are slightly higher (by about 6 per cent) than for herbicide application (US\$32 ha-1). However, the net returns for manual weeding are slightly higher (US\$599 ha-1 compared to US\$595 ha $\mathrm{ha}^{-1}$ ) due to superior weed control. Holding labour costs constant at US\$5 and increasing the initial weed density, the cost of manual weeding rises substantially while the cost of herbicide application is unchanged. This is primarily because the cost of manual weeding depends directly on weed numbers, whereas the cost of herbicides does not. Accordingly, the returns of herbicide application are superior at all weed densities above 5 plants $\mathrm{m}^{-2}$. The profit advantage of herbicide is positively related to the current weed density.

[Insert Table 3 near here]

Now examining the impact of labour costs, compare results across the columns of Table 3 . With increased labour cost, herbicide application is superior to manual weeding even at the lowest weed density (by US\$25 ha ${ }^{-1}$ or US\$54 ha-1 for the two higher labour costs). Finally, there is a positive interaction between high labour costs and high weed density, so that the profit advantage of herbicides is much greater again when both are present. At the highest weed density and the highest labour cost, herbicide application is approximately 80 per cent (about US\$200 ha ${ }^{-1}$ ) more profitable than manual weeding.

Overall, these findings highlight the optimality of post-emergence herbicide application, relative to manual weeding, as the primary form of weed control in rice farming systems if labour cost increases, and/or if weed density is relatively high. However, if labour costs increase, greater reliance is placed on herbicides and therefore the probability that herbicide resistance becomes more widespread also increases. This situation is further aggravated if weeds are not controlled optimally because a higher weed population promotes seed production that, in turn, makes weed-crop competition more intense.

The sensitivity analysis on the impact of labour cost involves the computation of complete factorial experiments for model results involving the six most important parameters identified in Section 2.8. The solutions presented here are for optimal weed control strategies for a scenario of very high labour cost (i.e. 200 per cent increase in the current price) and optimal weed threshold level $\left(0.1\right.$ plant $\left.\mathrm{m}^{-2}\right)$. The very high labour cost is used for 
illustration because it has the strongest implications for the relative economic performance of manual weeding and herbicide application strategies. Note that the methods of weed control adopted in both cases are held constant over 20 years, and therefore negative profits are also observed in some scenarios.

Figure 2 illustrates the profit difference between herbicide application and manual weeding given very high labour cost. (Positive differences indicate that herbicides are superior.) About 60 per cent of the scenarios investigated have a profit difference of zero, or close to zero. However, a minority of scenarios have high profit benefits for herbicides so, across all scenarios, the average profit advantage of herbicide application over manual weeding is around US\$8,000 ha-1. These results support the finding that when labour cost is high and a high density of weeds is present, herbicide application is likely to be the preferred strategy. They indicate that the finding is robust in the face of combinations of changes in the most sensitive parameters.

[Insert Figure 2 near here]

\section{Conclusions}

The complexity of analysing the implications of IWM strategies for rice production in the Philippines has motivated the development of the RIMPhil model. This framework provides a powerful tool for investigating the agricultural, biological, and economic implications of different integrated weed management strategies over a time horizon of up to 20 years.

A number of sample applications are presented. Model output emphasises the substantial benefits of effective long-term weed management strategies. The most-profitable weed densities are very low-lower than those usually achieved in farmers' fields. This indicates the importance of considering economic factors and weed population dynamics in the formulation of management recommendations for producers.

Model results indicate that a mixture of chemical and non-chemical treatments provides good weed control in rice crops, and maximises long-term profit for systems where the main weed is barnyardgrass. However, the performance of this strategy is influenced by labour costs and weed density level.

Results revealed that a high labour cost significantly influenced the economically preferred long-term weed management strategy. Herbicide application is the most valuable primary form of weed control in rice farming systems, relative to the regular use of manual weeding, if labour costs increase above current levels and/or the population of barnyardgrass plants is not maintained at its optimal level. This result is supported by an extensive sensitivity analysis, which shows that, under very high labour costs, herbicide is more profitable in about 40 per cent of scenarios (sometimes dramatically so), and is not less profitable in the other 60 per cent of scenarios.

Overall, the RIMPhil model provides a detailed, consistent framework to guide the efficient control of barnyardgrass in rice crops in the Philippines. Areas for further research include extension of the model to incorporate other weeds and rice farming systems, particularly overseas. We would also like to see collection of more field data on the population dynamics of barnyardgrass and other key weeds, to allow stronger calibration and validation of the model. 


\section{References}

Barrett, S.C.H. and Wilson, B.F., 1981. Colonizing ability in the Echinochloa crus-galli complex (barnyardgrass). I. Variation in life history. Can. J. Bot. 59, 1844-1860.

BAS, 2011. Bureau of Agricultural Statistics (BAS), CountrySTAT Philippines. [Online]. Available from URL: http://www.countrystat.bas.gov.ph [accessed 10 January 2011].

Bastiaans, L. and Kropff, M.J., 2003. WEEDS | Weed Competition. Encyclopedia of Applied Plant Sciences. Elsevier, Oxford, pp. 1494-1500.

Buhler, D.D., Hartzler, R.G. and Forcella, F., 1997. Implications of weed seedbank dynamics to weed management. Weed Sci. 45, 329-336.

De Datta, S.K. and Baltazar, A.M., 1996. Integrated weed management in rice in Asia, in: Naylor, R. (ed.), Herbicides in Asian Rice: Transitions in Weed Management. Palo Alto (California): Institute for International Studies, Stanford University and Manila (Philippines): International Rice Research Institute, pp. 145-166.

De Dios, J.L., Javier, E.F., Malabayabas, M.D., Casimero, M.C. and Espiritu, A.J., 2005. An overview of direct-seeding for rice crop establishment in the Philippines, in: Toriyama, K., Heong, K.L. and Hardy, B. (eds.), Rice is Life: Scientific Perspective for the 21st century. Proceedings of the World Rice Research Conference. IRRI and Japan International Research Center for Agricultural Sciences (CD-ROM), 4-7 November 2004, Tokyo and Tsukuba, Japan, pp. 189-192.

Doole, G. J. and Pannell, D. J., 2008. Optimisation of a large, constrained simulation model using compressed annealing. Agric. Econ. 59, 188-206.

Doole, G.J. and Weetman, E., 2009. Tactical management of pasture fallows in Western Australian cropping systems. Agric. Syst. 102, 24-32.

Draper, A.D., and Roy, B., 2002. Ryegrass RIM model stands the test of IWM field trial data. AgriBusiness Crop Updates 2002, pp. 49-50.

Egley, G.H., 1995. Seed germination in soil: dormancy cycles, in: Kigel, J. and Galili, G. (eds.), Seed Development and Germination. Marcel Dekker, Inc., New York, New York, USA, pp. 529-543.

Holm, L.G., Plucknett, D.L., Pancho, J.W. and Herberger, J.P., 1977. The World's Worst Weeds-Distribution and Biology. University Press of Hawaii, Honolulu Hawaii.

Janiya, J.D. and Johnson, D.E., 2008. Seedling emergence and survival of naturally occurring Echinochloa species in broadcast direct wet-seeded rice as affected by time of flooding. Paper Presented at the 39th Anniversary and Annual Conference of the Pest 
Management Council of the Philippines, 6-9 May 2008, Puerto Princessa City, Palawan, Philippines.

Johnson, D.E. and Mortimer, A.M., 2005. Issues for integrated weed management and decision support in direct-seeded rice, in: Toriyama, K., Heong, K.L. and Hardy, B. (eds.), Rice is Life: Scientific Perspective for the 21st century. Proceedings of the World Rice Research Conference. IRRI and Japan International Research Center for Agricultural Sciences (CD-ROM), 4-7 November 2004, Tokyo and Tsukuba, Japan, pp. 211-214.

Juliano, L.M., Casimero, M.C. and Llewellyn, R. (2010). Multiple herbicide resistance in barnyardgrass (Echinochloa crus-galli) in direct-seeded rice in the Philippines. Int. J. Pest Manage. 56, 299-307.

Kropff, M.J. and Lotz, L.A.P., 1993. Empirical models for crop-weed competition interactions, in: Kropff, M.J. and van Laar, H.H. (eds.), Modelling Crop-weed Interactions. CAB International, Wallingford, Oxon OX10 8DE, UK, pp. 9-23.

Maun, M.A. and Barrett, S.C.H., 1986. The biology of Canadian weeds. 77 Echinochloa crus-galli (L.) Beauv. Can. J. Plant Sci. 66, 739-759.

McCarl, B.A., and Apland, J.D., 1986. Validation of linear programming models. South. J. Agr. Econ. 18, 155-164.

Michael, P.W., 1983. Taxonomy and distribution of Echinochloa species with special reference to their occurrence as weeds of rice. Proceedings of the Conference on Weed Control in Rice. IRRI and International Weed Science Society (IWSS), 31 August-4 September 1981, IRRI, Los Baños, Laguna, Philippines, pp. 291-306.

Monjardino, M., Pannell, D.J. and Powles, S.B., 2003. Multispecies resistance and integrated management: a bioeconomic model for integrated management of rigid ryegrass (Lolium rigidum) and wild radish (Raphanus raphanistrum). Weed Sci. 51, 798-809.

Moody, K., 1990. Yield losses due to weeds in rice in the Philippines. Crop Loss Assessment in IRRI. International Rice Research Institute, Philippines, pp. 193-202.

Moody, K., 1994. Echinochloa crus-galli (L.) P. Beauv., in: Labrada, R., Caseley, J.C. and Parker, C. (eds.), Weed Management for Developing Countries. FAO Plant Production and Protection Paper, No. 120, FAO United Nations, Rome, Italy, pp. 5862.

Naylor, R., 1996. Herbicide use in Asian rice production: perspective from economics, ecology and the agricultural sciences, in Naylor, R. (ed.), Herbicides in Asian Rice: Transitions in Weed Management, Palo Alto (California): Institute for International 
Studies, Stanford University, and Manila (Philippines): International Rice Research Institute, pp. 3-26.

NEDA, 2010. National Economic and Development Authority (NEDA), National Economic Indicators. [Online]. Available from URL: http://www.neda.gov.ph [accessed 18 August 2010].

Pannell, D.J., 1997. Sensitivity analysis of normative economic models: theoretical framework and practical strategies. Agric. Econ. 16, 139-152.

Pannell, D.J., 2002. Human dimensions of integrated weed management, in: Spafford-Jacob, H., Dodd, J. and Moore, J.H. (eds), 13th Australian Weeds Conference: papers and proceedings. Plant Protection Society of Western Australia, Perth, pp. 8-115.

Pannell, D.J., 2006. Avoiding simplistic assumptions in discounting cash flows for private decisions, in: Pannell, D.J. and Schilizzi, S.G.M. (eds.), Economics and the Future, Time and Discounting in Private and Public Decision Making. Edward Elgar Publishing, Inc, Willian Pratt House, 9 Dewey Court, Northampton, Massachusetts 01060, USA, pp. 26-36.

Pannell, D.J., Marshall, G.R., Barr, N., Curtis, A., Vanclay, F. and Wilkinson, R., 2006.

Understanding and promoting adoption of conservation practices by rural landholders. Aust. J. Exp. Agric. 46, 1407-1424.

Pannell, D.J., Stewart, V., Bennett, A., Monjardino, M., Schmidt, C. and Powles, S.B., 2004. RIM: a bioeconomic model for integrated weed management of Lolium rigidum in Western Australia. Agric. Syst. 79, 305-325.

PhilRice, 2001. Management options for ricefields weeds. Rice Technology Bulletin 2001, No. 38. Philippine Rice Research Institute (PhilRice), Philippines.

PhilRice, 2007. Rice Figures in the Philippines. Philippine Rice Research Institute (PhilRice), Science City of Muñoz, Nueva Ecija, Philippines.

Pingali, P.L., Hossain, M. and Gerpacio, R.V., 1997. Asian Rice Bowls: The Returning Crisis? CAB International and International Rice Research Institute (IRRI), Los Banos.

Tran, D.V., 1997. World rice production: main issues and technical possibilities. Centre international de hautes études agronomiques Méditerranéennes (CIHEAM) 24, 1-13.

Valverde, B.E., Riches, C.R. and Caseley, J.C., 2000. Prevention and Management of Herbicide Resistant Weeds in Rice: Experiences from Central America with Echinochloa colona. S. A. Grafos, Cartago, Costa Rica. 
VanDevender, K.W., Costello, T.A., Ferguson, J.A., Huey, B.A., Slaton, N.A., Smith, R.J., Jr. and Helms, R.S., 1994. Weed management support system for rice producers. Appl. Eng. Agric. 10, 573-578.

Yabuno, T., 1983. Biology of Echinochloa species. Proceedings of the Conference on Weed Control in Rice. IRRI and International Weed Science Society (IWSS), 31 August-4 September 1981, IRRI, Los Baños, Laguna, Philippines, pp. 307-318. 
Table 1. Weed treatment options included in the RIMPhil model.

\begin{tabular}{|c|c|c|c|c|c|c|}
\hline & \multirow[t]{2}{*}{ Treatment } & \multirow[t]{2}{*}{ Type $^{\mathrm{a}}$} & \multicolumn{2}{|c|}{ Rate of kill } & \multicolumn{2}{|c|}{ Cost $\left(\right.$ PHP ha $\left.{ }^{-1}\right)$} \\
\hline & & & $\mathrm{TR}^{\mathrm{b}}$ & $\mathrm{DR}^{\mathrm{c}}$ & & \\
\hline 1 & Stale-seedbed (mechanical) & $\mathrm{NC}$ & 98 & 98 & 2250 & \\
\hline 2 & Stale-seedbed+glyphosate & $\mathrm{C}$ & 97 & 97 & 1998 & \\
\hline 3 & Stale-seedbed+paraquat & $\mathrm{C}$ & 97 & 97 & 2110 & \\
\hline 4 & Reduced tillage & $\mathrm{NC}$ & 80 & 80 & $* *$ & \\
\hline 5 & Reduced tillage+glyphosate & $\mathrm{C}$ & 90 & 90 & 648 & \\
\hline 6 & Reduced tillage+paraquat & $\mathrm{C}$ & 90 & 90 & 760 & \\
\hline 7 & Full land cultivation & $\mathrm{NC}$ & 90 & 90 & 675 & \\
\hline 8 & Poor quality/farmer's seeds (FS) & $\mathrm{NC}$ & 0 & 0 & costs $\mathrm{C}$ & on SD used ${ }^{\mathrm{d}}$ \\
\hline 9 & High quality/certified seeds (CS) & $\mathrm{NC}$ & 10 & 10 & costs $\mathrm{c}$ & on SD used ${ }^{\mathrm{e}}$ \\
\hline 10 & Manual seeding & $\mathrm{NC}$ & - & 0 & $* *$ & \\
\hline \multirow[t]{2}{*}{11} & Mechanical seeding (drumseeder) & $\mathrm{NC}$ & - & 0 & 550 & \\
\hline & Seeding rate $(\mathrm{SD}) * * *$ & & & & ${ }^{\mathrm{d}} \mathrm{FS}$ & ${ }^{\mathrm{e}} \mathrm{CS}$ \\
\hline 12 & Use $50 \mathrm{~kg} / \mathrm{ha}$ & $\mathrm{NC}$ & $*$ & $*$ & 0 & 825 \\
\hline 13 & Use $100 \mathrm{~kg} / \mathrm{ha}$ & $\mathrm{NC}$ & $*$ & $*$ & 675 & 2325 \\
\hline 14 & Use $150 \mathrm{~kg} / \mathrm{ha}$ & $\mathrm{NC}$ & $*$ & $*$ & 1350 & 3825 \\
\hline 15 & Use $200 \mathrm{~kg} / \mathrm{ha}$ & $\mathrm{NC}$ & $*$ & $*$ & 2025 & 5325 \\
\hline 16 & Use $300 \mathrm{~kg} / \mathrm{ha}$ & $\mathrm{NC}$ & $*$ & $*$ & 3375 & 8325 \\
\hline 17 & Butachlor (Group K3) & $\mathrm{H}$ & 90 & - & 706 & \\
\hline 18 & Butachlor+safener (Group K3) & $\mathrm{H}$ & 90 & 90 & 938 & \\
\hline 19 & Pretilachlor (Group K3) & $\mathrm{H}$ & 85 & - & 975 & \\
\hline 20 & Pretilachlor+fenclorim (Group K3) & $\mathrm{H}$ & 85 & 85 & 850 & \\
\hline 21 & Oxadiazon (Group E) & $\mathrm{H}$ & 80 & 85 & 991 & \\
\hline 22 & Pendimethalin (Group K1) & $\mathrm{H}$ & 90 & - & 900 & \\
\hline 23 & Thiobencarb (Group N) & $\mathrm{H}$ & 90 & 90 & 1300 & \\
\hline 24 & Bensulfuron+flufenacet (Group B and K3) & $\mathrm{H}$ & 85 & 85 & 885 & \\
\hline 25 & Metsulfuron+chlorimuron-ethyl (Group B) & $\mathrm{H}$ & 85 & 85 & 829 & \\
\hline 26 & Other pre-emergence herbicide $* * * *$ & $\mathrm{H}$ & 0 & 0 & 250 & \\
\hline 27 & Irrigate field 5-7 DAT at $2-3 \mathrm{~cm}$ & $\mathrm{NC}$ & 70 & - & 500 & \\
\hline 28 & Irrigate field $7-10$ DAS at $2-3 \mathrm{~cm}$ & $\mathrm{NC}$ & - & 50 & 500 & \\
\hline 29 & Cyhalofop-butyl (Group A) & $\mathrm{H}$ & 95 & 95 & 1425 & \\
\hline 30 & Pyribenzoxim (Group B) & $\mathrm{H}$ & 95 & 95 & 1450 & \\
\hline 31 & Pendimethalin (Group K1) & $\mathrm{H}$ & 85 & - & 900 & \\
\hline 32 & Penoxsulam (Group B) & $\mathrm{H}$ & 95 & 95 & 1330 & \\
\hline 33 & Anilofos+ethoxysulfuron (Group K3 and B2) & $\mathrm{H}$ & 85 & 85 & 983 & \\
\hline 34 & Butachlor+propanil (Group K3 and C2) & $\mathrm{H}$ & 85 & 85 & 1072 & \\
\hline 35 & Piperophos+2,4-D (Group K3 and O) & $\mathrm{H}$ & 85 & 85 & 788 & \\
\hline 36 & Thiobencarb+2,4-D (Group N and O) & $\mathrm{H}$ & 85 & 85 & 1012 & \\
\hline 37 & Fentrazamide+propanil (Group K3 and C2) & $\mathrm{H}$ & 90 & 90 & 1484 & \\
\hline 38 & Other early post-emergence herbicide $* * * *$ & $\mathrm{H}$ & 0 & 0 & 250 & \\
\hline 39 & Manual weeding at $15-30$ DAT/DAS & $\mathrm{NC}$ & 100 & 95 & costs $\mathrm{C}$ & 1 on $\mathrm{WD}^{\mathrm{f}}$ \\
\hline 40 & Mechanical weeding at $15-30$ DAT/DAS & $\mathrm{NC}$ & 90 & 85 & costs $\mathrm{C}$ & 1 on WD \\
\hline 41 & Bispyribac sodium (Group B) & $\mathrm{H}$ & 95 & 95 & 1586 & \\
\hline 42 & Cyhalofop-butyl (Group A) & $\mathrm{H}$ & 95 & 95 & 1425 & \\
\hline 43 & Thiobencarb (Group N) & $\mathrm{H}$ & 90 & 90 & 1300 & \\
\hline 44 & Fenoxaprop-p-ethyl (Group A) & $\mathrm{H}$ & 90 & 90 & 1282 & \\
\hline 45 & Metsulfuron+chlorimuron-ethyl (Group B) & $\mathrm{H}$ & 85 & 85 & 829 & \\
\hline 46 & Penoxsulam+cyhalofop (Group B and A) & $\mathrm{H}$ & 95 & 95 & 1450 & \\
\hline 47 & Other late post-emergence herbicide $* * *$ & $\mathrm{H}$ & 0 & 0 & 250 & \\
\hline 48 & Manual weeding at 31-45 DAT/DAS & $\mathrm{NC}$ & 95 & 95 & costs $\mathrm{C}$ & on WD density \\
\hline 49 & Mechanical weeding at 31-45 DAT/DAS & $\mathrm{NC}$ & 95 & 95 & costs $\mathrm{C}$ & on WD density \\
\hline
\end{tabular}

${ }^{a} \mathrm{NC}=$ non chemical, $\mathrm{C}=$ chemical and non chemical, $\mathrm{H}=$ chemical. ${ }^{\mathrm{b}} \mathrm{TR}=$ transplanted rice. ${ }^{\mathrm{c}} \mathrm{DR}=$ direct-seeded rice. ${ }^{d} \mathrm{FS}=$ poor/farmer's seeds. ${ }^{\mathrm{e}} \mathrm{CS}=$ certified seeds. ${ }^{\mathrm{f}} \mathrm{WD}=$ weed density. ${ }^{*}$ Depends on crop and weed densities. ** Costs are included in non-weed control costs. *** The costs of seeding rate are just the additional charges of 

planning horizon.

\begin{tabular}{|c|c|c|c|}
\hline \multicolumn{2}{|c|}{ Weed control scenario } & \multirow{2}{*}{$\begin{array}{l}\text { EAP } \\
\left(\mathrm{US} \$ \mathrm{ha}^{-1}\right) \\
-293\end{array}$} & \multirow{2}{*}{$\begin{array}{l}\begin{array}{l}\text { Final weed density } \\
\left(\text { plants } \mathrm{m}^{-2}\right)\end{array} \\
20,700\end{array}$} \\
\hline CFS & Conventional farming system (base scenario) & & \\
\hline & Innovative farming system (base scenario) & -210 & 16,320 \\
\hline \multicolumn{4}{|c|}{ Chemical control only } \\
\hline 1a & CFS with application of $\mathrm{PEH}^{\mathrm{a}}$ & -247 & 3,327 \\
\hline $1 \mathrm{~b}$ & IFS with application of PEH & -184 & 2,189 \\
\hline $1 \mathrm{c}$ & 1a with one $\mathrm{POST}^{\mathrm{b}}$ application & 1,043 & 21 \\
\hline $1 \mathrm{~d}$ & $1 \mathrm{~b}$ with one $\mathrm{POST}^{\mathrm{b}}$ application & 402 & 58 \\
\hline 1e & $1 \mathrm{~d}$ with low seeding rate replaced by high seeding rate & 1,363 & $<0.01$ \\
\hline 1f & 1c with another application of POST (i.e. 2x POST) & 1,150 & $<0.01$ \\
\hline $1 \mathrm{~g}$ & 1d with another application of POST (i.e. 2x POST) & 1,432 & $<0.01$ \\
\hline \multicolumn{4}{|c|}{ Non-chemical control } \\
\hline 2a & CFS with use of water management & -295 & 11,374 \\
\hline $2 b$ & IFS with use of water management & -217 & 8,965 \\
\hline $2 \mathrm{c}$ & 2a with water management replaced by stale seedbed & -384 & 18,187 \\
\hline $2 d$ & $2 \mathrm{~b}$ with water management replaced by stale seedbed & -310 & 8,456 \\
\hline $2 \mathrm{e}$ & 2a with use $\mathrm{DS}^{\mathrm{c}}$ for seeding and $1 \mathrm{x} \mathrm{HW}$ application & $-43,176$ & 624 \\
\hline $2 \mathrm{f}$ & 2b with use $\mathrm{DS}^{\mathrm{c}}$ for seeding and 1x HW application & $-41,910$ & 483 \\
\hline $2 \mathrm{~g}$ & 2e with another application of HW (i.e. 2x HW) & 1,245 & $<0.01$ \\
\hline $2 \mathrm{~h}$ & $2 \mathrm{f}$ with another application of HW (i.e. $2 x \mathrm{HW}$ ) & 1,518 & $<0.01$ \\
\hline $2 \mathrm{i}$ & $2 \mathrm{~g}$ with $2 \mathrm{x} \mathrm{HW}$ replaced by $2 \mathrm{x} \mathrm{MW}^{\mathrm{e}}$ applications & 1,231 & $<0.01$ \\
\hline $2 \mathrm{j}$ & $2 \mathrm{~h}$ with $2 \mathrm{x} \mathrm{HW}$ replaced by $2 \mathrm{x}$ MW applications & 1,267 & $<0.01$ \\
\hline \multicolumn{4}{|c|}{ Non-chemical and chemical control } \\
\hline $3 \mathrm{a}$ & CFS with water management and PEH application & -191 & 1,718 \\
\hline $3 \mathrm{~b}$ & IFS with water management and PEH application & -154 & 1,138 \\
\hline $3 \mathrm{c}$ & 3a with use $\mathrm{DS}^{\mathrm{c}}$ for seeding and $1 \mathrm{x} \mathrm{HW}$ application & 1,221 & $<0.01$ \\
\hline $3 \mathrm{~d}$ & $3 \mathrm{~b}$ with use $\mathrm{DS}^{\mathrm{c}}$ for seeding and $1 \mathrm{x} \mathrm{HW}$ application & 1,471 & $<0.01$ \\
\hline $3 \mathrm{e}$ & 3c with another application of HW (i.e. $2 x \mathrm{HW}$ ) & 1,529 & $<0.01$ \\
\hline $3 \mathrm{f}$ & 3d with another application of HW (i.e. 2 x HW) & 1,513 & $<0.01$ \\
\hline $3 g$ & $3 \mathrm{c}$ with $1 \mathrm{x}$ HW replaced by $1 \mathrm{x}$ MW application & 413 & 157 \\
\hline $3 \mathrm{~h}$ & 3d with 1x Hw replaced by 1x MW application & 180 & 130 \\
\hline $3 \mathrm{i}$ & 3g with another application of MW (i.e. 2x MW) & 1,462 & $<0.01$ \\
\hline $3 \mathrm{j}$ & 3h with another application of MW (i.e. 2x MW) & 1,461 & $<0.01$ \\
\hline $3 \mathrm{k}$ & 3a with one POST application & 1,185 & $<0.01$ \\
\hline 31 & 3b with one POST application & 1,449 & 0.01 \\
\hline $3 \mathrm{~m}$ & 3k with another application of POST (i.e. 2x POST) & 1,129 & $<0.01$ \\
\hline $3 n$ & 31 with another application of POST (i.e. $2 x$ POST) & 1,407 & $<0.01$ \\
\hline
\end{tabular}

${ }^{a}$ PEH: pre-emergence herbicides. ${ }^{b}$ POST: post-emergence herbicides. ${ }^{c}$ DS: drumseeder. ${ }^{d}$ HW: hand/manual weeding. ${ }^{\mathrm{e}} \mathrm{MW}$ : mechanical weeding. 
4 Table 3. Treatment cost and net return differences of manual weeding and herbicide application for direct5 seeded rice under different labour costs and weed densities for one cropping season. Positive values for net 6 return difference indicate that herbicide application is superior.

\begin{tabular}{|c|c|c|c|c|c|c|c|c|}
\hline \multirow{3}{*}{$W^{a}$} & & & \multicolumn{6}{|c|}{ Labour cost (US\$ man-day $\left.{ }^{-1}\right)$} \\
\hline & & & \multicolumn{2}{|c|}{ Current (US\$5) } & \multicolumn{2}{|c|}{ High (US\$11) } & \multicolumn{2}{|c|}{ Very High (US\$17) } \\
\hline & & & $\mathrm{MW}^{\mathrm{b}}$ & $\mathrm{HA}^{\mathrm{b}}$ & MW & HA & MW & HA \\
\hline 5 & $\begin{array}{l}\text { Treatment } \\
\left(\mathrm{US} \$ \mathrm{ha}^{-1}\right)\end{array}$ & cost & 34 & 32 & 69 & 37 & 103 & 43 \\
\hline \multirow{3}{*}{10} & $\begin{array}{l}\text { Net } \\
\text { difference } \\
\mathrm{ha}^{-1} \text { ) }\end{array}$ & $\begin{array}{r}\text { returns } \\
\text { (US\$ }\end{array}$ & 599 & 595 & 532 & 556 & 464 & 517 \\
\hline & $\begin{array}{l}\text { Treatment } \\
\left(\mathrm{US} \$ \mathrm{ha}^{-1}\right)\end{array}$ & cost & 52 & 32 & 104 & 37 & 157 & 43 \\
\hline & $\begin{array}{l}\text { Net } \\
\text { difference } \\
\mathrm{ha}^{-1} \text { ) }\end{array}$ & $\begin{array}{r}\text { returns } \\
\text { (US\$ }\end{array}$ & 568 & 582 & 483 & 543 & 397 & 504 \\
\hline \multirow[t]{2}{*}{15} & $\begin{array}{l}\text { Treatment } \\
\left(\text { US } \$ \mathrm{ha}^{-1}\right)\end{array}$ & cost & 74 & 32 & 148 & 37 & 223 & 43 \\
\hline & $\begin{array}{l}\text { Net } \\
\text { difference } \\
\text { ha }^{-1} \text { ) }\end{array}$ & $\begin{array}{r}\text { returns } \\
\text { (US\$ }\end{array}$ & 527 & 563 & 419 & 524 & 312 & 485 \\
\hline \multirow[t]{2}{*}{20} & $\begin{array}{l}\text { Treatment } \\
\left(\mathrm{US} \$ \mathrm{ha}^{-1}\right)\end{array}$ & cost & 87 & 32 & 174 & 37 & 261 & 43 \\
\hline & $\begin{array}{l}\text { Net } \\
\text { difference } \\
\mathrm{ha}^{-1} \text { ) }\end{array}$ & $\begin{array}{r}\text { returns } \\
\text { (US\$ }\end{array}$ & 502 & 551 & 382 & 512 & 261 & 473 \\
\hline
\end{tabular}

${ }^{a}$ WD: weed density (plants $\mathrm{m}^{-2}$ ). Note that this is the weed density present at the time of performing manual weeding or herbicide application in the rice fields. ${ }^{\mathrm{b}} \mathrm{MW}$ : manual weeding, and HA: herbicide application. 


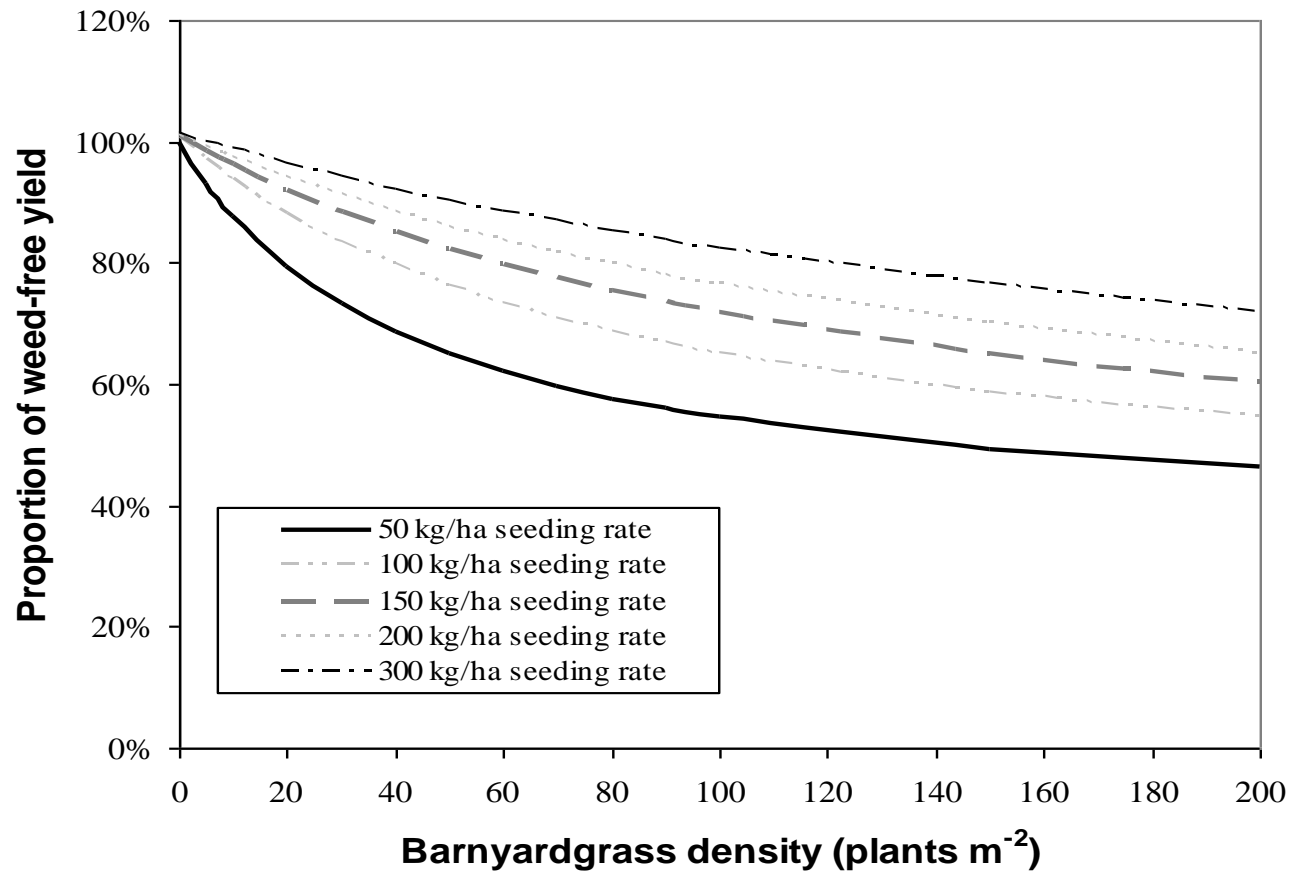

8

\section{Barnyardgrass density (plants $\mathbf{~}^{-2}$ )}

9 Figure 1. Relationship between rice crop yield and barnyardgrass density.

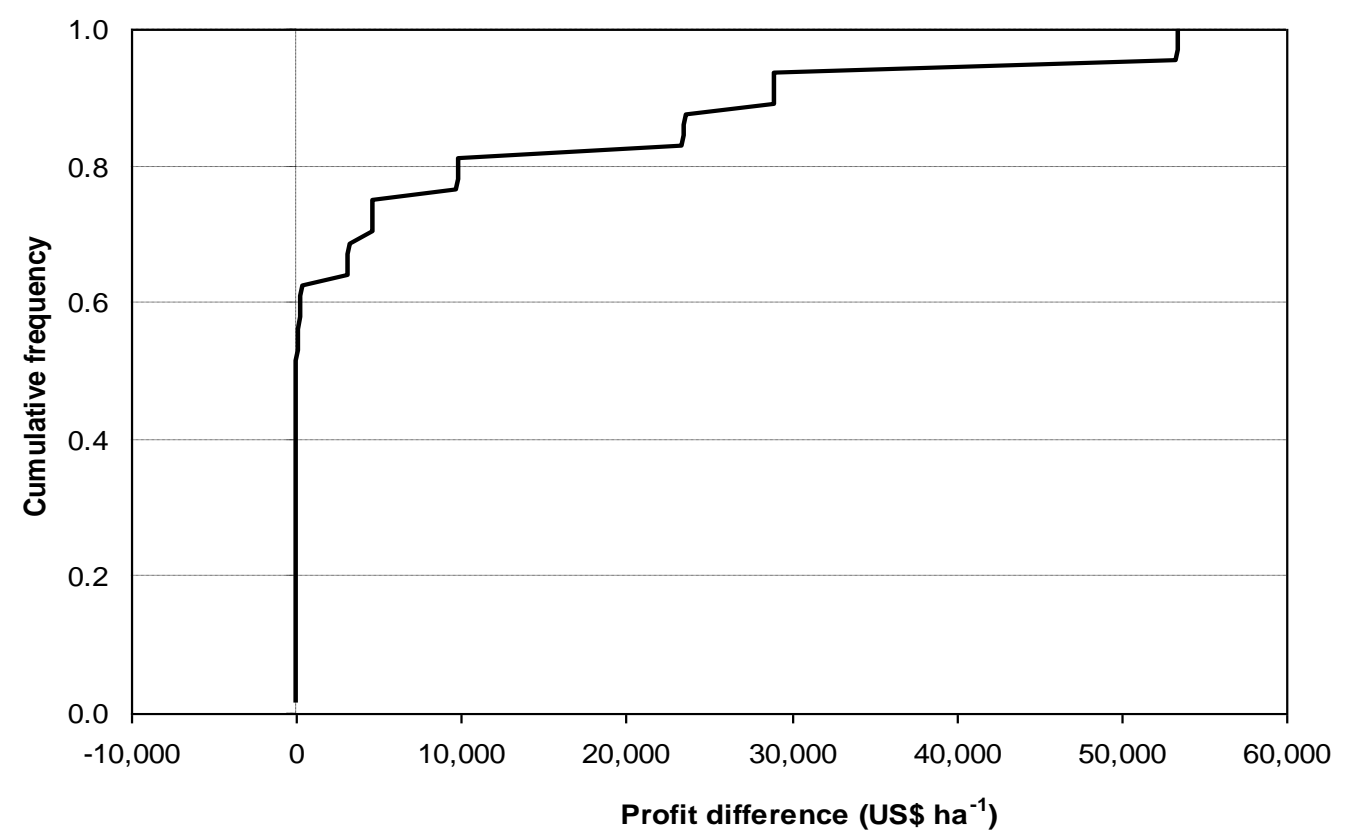

11 Figure 2. Cumulative distribution function for the profit difference (US\$ ha ${ }^{-1}$ ) between herbicide application and 12 extensive use of manual weeding strategies with direct-seeding over 20 years. Positive values indicate that 13 herbicide application is superior. 